\title{
Episode of toxic gas exposure in sewer workers
}

\author{
Monika M Watt, Stephen J Watt, Anthony Seaton
}

\begin{abstract}
Objectives-Sewer workers are used to unpleasant smells, but may be required to investigate unusual ones. Twenty six men were involved in investigation of episodes of such a smell after neighbourhood complaints over several weeks.

Methods-Workers exposed to the smell were investigated by clinical follow up, lung function tests, and measurement of pituitary function.

Results -14 of the 26 developed subacute symptoms including sore throat, cough, chest tightness, breathlessness, thirst, sweating, irritability, and loss of libido. Severity of symptoms seemed to be dose related. Minor symptoms resolved over several weeks but those more seriously affected have shown deteriorating respiratory symptoms and lung function and remain unable to work a year after the incident. In one, evidence of mild cranial diabetes insipidus was found. Analysis of gas from the sewer showed the presence of a mixture of thiols and sulphides, known to be highly odorous and not normally found in sewers. The source remains unknown.
\end{abstract}

Conclusions-Several of these men seem to have developed delayed airways disease and disturbances of hypothalamic function. Such an outcome has not to our knowledge been described before. Despite the presence of the smell, standard safety gas detection equipment used to ensure the sewer was safe to enter failed to indicate the presence of a hazard. Protection against such incidents can only be provided by the use of positive pressure breathing apparatus.

(Occup Environ Med 1997;54:277-280)

Occupational

Medicine, University

of Aberdeen

M M Watt

S J Watt

A Seaton

Correspondence to:

Dr Monika M Watt,

Department of

Environmental and

Occupational Medicine,

University Medical School,

Foresterhill, Aberdeen

AB9 2ZD.

Accepted 20 November 1996 by chest and occupational physicians to the United Kingdom SWORD project from 1989 to 1991 , and the incidence seems to be ris- ing. ${ }^{2}$ Inhalation accidents are an acute injury, and provided the acute episode is survived without neurological sequelae, complete recovery usually occurs. However, exposure to irritant gases may occasionally result in the longer term respiratory illnesses bronchiolitis, reactive airways dysfunction syndrome, and pulmonary fibrosis, and a few people are unable to return to their work. ${ }^{3}$ Exposure to toxic gas is a well recognised hazard for sewer workers who work in enclosed spaces where gas arising from the decomposition of waste material and from industrial effluent may be encountered. The main risks involve hypoxia and exposure to poisons-such as hydrogen sulphide. Standard safety procedures include gas analysis to ensure the presence of adequate oxygen and the absence of methane or hydrogen sulphide. We report here an episode of inhalation injury in sewer workers, which resulted in subacute and chronic respiratory and other symptoms not previously described and which has important implications for the safety of all such workers.

The incident

Over a two month period numerous complaints were received from the public of a "gas like" odour in a localised urban district. On each occasion a similar sequence of events occurred: the gas authority was called to investigate but found no evidence of a gas leak, and then water services staff were called to investigate the sewer system as a source. If the odour seemed to arise from the sewer, manhole covers were lifted and the sewers were flushed with water. On one occasion a more pronounced odour lasting several hours led to the area being cordoned off by police. The source of the "gas-like" smell was investigated by police, fire brigade, gas, and water authorities without success. During this incident the occupational health service was called as a number of water services personnel reported symptoms of acute eye and throat irritation. The site was visited by the occupational physician and arrangements were made for medical examination of the personnel involved the next day. As a result of these examinations all workers involved in the investigation of any incident were recalled for examination. 


\section{Affected workers}

Twenty six men who had been members of teams called to investigate the smell were identified and all were examined. Twelve had not been aware of the smell, reported no symptoms, and had no abnormal clinical features. These men had not been in the immediate vicinity of the sewers. The remaining 14 had experienced the smell and reported symptoms which they had initially ascribed to current illness. All had worked either within or in the immediate vicinity of sewers. Seven who had not entered the sewer system, complained of sore throat and influenza-like symptoms which developed within the first 12 to 24 hours after exposure, and lasted from a few days to several weeks. All recovered fully. The remaining seven men had a history of greater exposure having either worked in sewers or manholes or been exposed for a long period. This group had more serious and persistent symptoms of cough, chest discomfort, breathlessness, and fatigue, all of which developed over a few days. The more severely affected men also complained of thirst, sweating, irritability, and loss of libido. Initially the only abnormality on clinical examination was considerable inflammation of the soft palate and throat. This persisted for several weeks. Those with breathlessness and chest discomfort were unable to perform a forced expiratory manoeuvre adequately. Of this group, two recovered completely over a period of two months but five developed persistent symptoms. None had previously encountered a similar smell in the course of his work. Case histories of those with persistent symptoms are described and the table shows the results of pulmonary function tests.

\section{Case reports}

CASE 1

A 41 year old man investigated the smell on several occasions. During one incident he was in the sewer for 90 minutes where he found and removed a broken iron gas pipe which smelt strongly. Within 24 hours he developed a sore throat, nasal stuffiness, and cough, and thought he had influenza. He became increasingly breathless with wheeze and chest tightness over the next few weeks. He had no respiratory medical history but had smoked 20 cigarettes daily for 20 years. A chest radiograph was normal. He was treated with prednisolone then inhaled steroids which improved forced expiratory volume in one second $\left(\mathrm{FEV}_{1}\right)$. Thereafter his symptoms showed little further improvement. He had a persistent dry throat and drank excess fluids. He complained of irritability, excessive sweating, and loss of libido. One year after the incident, his lung volumes remain impaired (table). A water deprivation test showed no evidence of diabetes insipidus and other tests of endocrine function including thyroid function, follicle stimulating hormone (FSH), luteinising hormone ( $\mathrm{LH})$, prolactin, and testosterone concentrations were normal. He has remained incapacitated from work by symptoms of breathlessness and chest discomfort.

\section{CASE 2}

A 52 year old male supervisor investigated the smell on several occasions. He was never in a sewer for more than 30 minutes when the smell was present. On one occasion he was exposed in the vicinity of an open manhole for several hours. He reported a sore throat, cough, and breathlessness with some wheeze developing within 48 hours of this exposure. He was a smoker of 10-15 cigarettes daily. His chest radiograph was normal. Lung function tests showed evidence of a mild obstructive pattern similar to results before the incident. An exercise test showed no lability of peak expiratory flow rate (PEFR) after exercise but a methacholine challenge test showed evidence of hyperreactivity-the provocative dose $\left(\mathrm{PD}_{20}\right.$ ) being $1.0 \mu \mathrm{g}$ (normal $>16 \mu \mathrm{g}$ ). He was treated with bronchodilators and inhaled steroids but with little benefit. He continued to complain of exertional breathlessness and cough provoked by exposure to a variety of irritants including car exhaust and cigarette smoke. He also complained of fatigue, excessive thirst, sweating, loss of libido, and had episodes of panic. The sore throat and thirst

Pulmonary function test results

\begin{tabular}{|c|c|c|c|c|c|c|c|c|}
\hline & \multirow{2}{*}{$\begin{array}{l}\text { Predicted } \\
\text { normal } \\
\text { value }\end{array}$} & \multirow{2}{*}{$\begin{array}{l}\text { Before } \\
\text { exposure }\end{array}$} & \multicolumn{2}{|c|}{ After exposure } & \multirow[b]{2}{*}{3 months } & \multirow[b]{2}{*}{6 months } & \multirow[b]{2}{*}{9 months } & \multirow[b]{2}{*}{12 months } \\
\hline & & & 2 weeks & 1 month & & & & \\
\hline \multicolumn{9}{|l|}{ Case 1: } \\
\hline FEV & $3 \cdot 7$ & & $2 \cdot 6$ & 1.9 & $2 \cdot 4$ & $2 \cdot 4$ & $2 \cdot 3$ & $2 \cdot 0$ \\
\hline FVC & $4 \cdot 5$ & - & $3 \cdot 7$ & $3 \cdot 0$ & $3 \cdot 35$ & $3 \cdot 3$ & $3 \cdot 3$ & $3 \cdot 1$ \\
\hline Tleco & $9 \cdot 5$ & - & - & $8 \cdot 6$ & -.. & $8 \cdot 9$ & $9 \cdot 7$ & $7 \cdot 7$ \\
\hline \multicolumn{9}{|l|}{ Case 2: } \\
\hline $\mathrm{FEV}_{1}$ & $4 \cdot 1$ & $3 \cdot 6$ & 3.55 & $3 \cdot 4$ & $3 \cdot 0$ & $3 \cdot 0$ & $2 \cdot 7$ & $2 \cdot 2$ \\
\hline FVC & $5 \cdot 2$ & $5 \cdot 1$ & $5 \cdot 1$ & $5 \cdot 5$ & $4 \cdot 6$ & $3 \cdot 9$ & $4 \cdot 2$ & $3 \cdot 7$ \\
\hline Tleco & $10 \cdot 5$ & - & - & $7 \cdot 1$ & 6.5 & $6 \cdot 4$ & $5 \cdot 9$ & $7 \cdot 3$ \\
\hline \multicolumn{9}{|l|}{ Case 3: } \\
\hline $\mathrm{FEV}_{1}$ & $3 \cdot 3$ & $3 \cdot 0$ & $2 \cdot 9$ & $3 \cdot 0$ & $2 \cdot 7$ & $2 \cdot 9$ & $2 \cdot 7$ & $2 \cdot 5$ \\
\hline FVC & $4 \cdot 0$ & $3 \cdot 8$ & $3 \cdot 9$ & $4 \cdot 0$ & $3 \cdot 3$ & $3 \cdot 8$ & $3 \cdot 6$ & $3 \cdot 7$ \\
\hline Ti.co) & $8 \cdot 4$ & & - & $8 \cdot 5$ & $7 \cdot 7$ & $7 \cdot 3$ & $6 \cdot 7$ & $6 \cdot 3$ \\
\hline \multicolumn{9}{|l|}{ Case 4: } \\
\hline $\mathrm{FEV}_{\mathrm{i}}$ & $4 \cdot 6$ & $4 \cdot 8$ & $4 \cdot 9$ & $4 \cdot 6$ & $4 \cdot 8$ & - & - & 4.5 \\
\hline FVC & $5 \cdot 3$ & $5 \cdot 9$ & $6 \cdot 0$ & $6 \cdot 0$ & $6 \cdot 1$ & - & & $5 \cdot 6$ \\
\hline \multirow{2}{*}{\multicolumn{9}{|c|}{ Case 5: }} \\
\hline & & & & & & & & \\
\hline $\mathrm{FEV}_{\mathrm{i}}$ & $4 \cdot 6$ & $4 \cdot 5$ & $3 \cdot 4$ & $3 \cdot 6$ & - & $4 \cdot 5$ & - & - \\
\hline FVX & $5 \cdot 6$ & $5 \cdot 5$ & $4 \cdot 5$ & $4 \cdot 1$ & $\ldots$ & $5 \cdot 6$ & $\ldots$ & - \\
\hline Tico & $12 \cdot 0$ & - & - & $10 \cdot 8$ & - & - & - &.- \\
\hline
\end{tabular}

FEV: (l); FVC (1); Ti.co mmol.min 'kpa 
settled over a few months, but he complained of increasing breathlessness on exertion. One year after the incident, lung volumes have deteriorated (table). A water deprivation test showed no significant increase in plasma osmolality with only a minimal increase in urinary osmolality to $452 \mathrm{mOsm} / \mathrm{kg}$. After $2 \mathrm{mg}$ desmopressin (DDAVP), urinary osmolality rose to $791 \mathrm{mOsm} / \mathrm{kg}$ consistent with a diagnosis of cranial diabetes insipidus. Other tests of endocrine function including thyroid function, FSH, LH, prolactin, and testosterone were all normal. High resolution computed tomography (HRCT) of the chest showed widespread focal centrilobular emphysema in all lobes but more notable in the upper zones. This was considered to be consistent with his smoking history and airway obstruction before the incident. He has been unable to return to work.

CASE 3

A 51 year old male sewage worker was exposed on several occasions over a few weeks. He opened manholes but only briefly entered the sewers on a few occasions. He complained of sore throat, cough, and breathlessness on exertion. Over a few weeks he developed thirst, excessive sweating, irritability, and loss of libido. On examination he had no obvious abnormality other than inflammation of the throat. A chest radiograph was normal and lung function tests showed evidence of a mild obstructive defect. He had smoked 20 cigarettes daily for 30 years. An exercise test showed no evidence of bronchial lability but methacholine challenge showed $\mathrm{PD}_{20}$ of $2 \cdot 2$ $\mu \mathrm{g}$. He was treated with bronchodilators and inhaled steroids. Over the next few months he continued to be troubled by cough often provoked by exposure to car exhaust, cigarette smoke, or hair spray. Most of these symptoms resolved but he remains persistently breathless on exertion and both lung volumes and diffusing capacity have deteriorated (table). Chest HRCT showed evidence of some bullae at the apices but no other abnormality. A water deprivation test was normal, and thyroid function, FSH, LH, prolactin, and testosterone concentrations were also normal. $\mathrm{He}$ has remained unable to return to his work as a result of exertional breathlessness.

\section{CASE 4}

A 34 year old male worker who had previously been very fit, playing football at local club level, was exposed on one day when he was close to an open manhole for several hours and on several subsequent occasions when he lifted manhole covers. He developed a sore throat with cough, and then chest tightness, wheeze, and breathlessness on exertion. Later he reported thirst, excessive sweating, irritability, and loss of libido. He had no history of respiratory illness but had smoked 20 cigarettes daily for almost 20 years. Lung function tests were normal apart from a minor reduction in diffusing capacity. A chest radiograph was normal. An exercise test showed no evidence of bronchial lability and methacholine chal- lenge was normal $\left(\mathrm{PD}_{20}>16 \mu \mathrm{g}\right)$. Over the next four months his symptoms showed a progressive improvement and he returned to work four months after the incident but did not regain his previous physical fitness and was unable to play football. A water deprivation test showed no evidence of diabetes insipidus and other tests of endocrine function including thyroid function, FSH, LH, prolactin, and testosterone were all normal.

\section{CASE 5}

A 25 year old male worker was exposed working close to an open manhole for several hours. He neither lifted the manhole cover nor entered the sewer. Next day he developed cough with sputum, central chest soreness, and breathlessness. He had no history of respiratory illness but had smoked 20 cigarettes daily for nine years. Lung function showed a considerable fall in $\mathrm{FEV}_{1}$ compared with results before the incident. A chest radiograph was normal. An exercise test showed no evidence of bronchial lability. He had no treatment and was well with no symptoms six months after the incident when lung function had returned to normal.

\section{Investigation}

Standard safety procedure on identification of the smell on the site before entry to a sewer involved the use of portable gas analysis equipment to measure oxygen concentration and to test for the presence of flammable gases and hydrogen sulphide. These analyses failed to detect any abnormality. During the occupational physician's site visit, "grab" samples of gas and of sewage were taken for analysis by water services laboratories. Repeat samples were taken after the smell had dispersed. The samples were analysed by gas chromatography and showed the presence of a wide range of compounds containing sulphur which are not normally present in sewers and which were not present in repeat samples taken after the smell had gone. The principal volatile compounds detected associated with the smell were disulphides and thiophenes, the most readily detectable being diethyl disulphide and dimethyl disulphide. The analyses were not quantitative and it is not possible to relate symptoms to any specific compound identified.

\section{Discussion}

This incident shows several problems posed by the occurrence of a previously unrecognised hazard. Although the risks of exposure to toxic gases are well recognised during work in sewers, the principal hazards are hypoxia due to the accumulation of methane and carbon dioxide, hydrogen sulphide poisoning and explosive risk as a result of flammable gases. Standard safety procedures reflect these hazards. In this incident it was not surprising that the smell was initially thought to be domestic gas as the odour of natural gas is provided by the addition of trace amounts of mercaptans 
and sulphides. After the gas engineers were satisfied that the smell was not due to domestic gas, the water authority's gas detection equipment did not identify any of the known hazards, and despite the smell, the sewers were presumed safe to enter. Unfortunately because the initial symptoms were delayed, minor, and attributed to current illness, the failure of this safety procedure was unrecognised and further exposures occurred. The possible presence of an unidentified toxic agent was not appreciated.

The symptoms associated with exposure were unusual in that they were minimal at the time of exposure, but became increasingly obvious over a period of several days, and also because various non-respiratory symptoms occurred. The pattern of respiratory symptoms suggests that the toxic agent was probably water soluble and caused a subacute inflammation of the palate, pharynx, and large airways. This resolved very slowly and probably explains the symptoms in all but the most severely affected people. Those with more notable respiratory symptoms had airflow obstruction and features suggestive of reactive airways dysfunction syndrome although the lack of immediate symptoms at the time of exposure is not consistent with the strict diagnostic criteria proposed by Brooks et al. ${ }^{45}$ The continued deterioration in lung function found in two affected workers suggested the possible development of bronchiolitis but HRCT has not confirmed this

The presence of other symptoms, which included chronic fatigue, thirst, irritability, sweating, and loss of libido, raised the possibility that the toxic agent may also have caused central neurological effects. The mild cranial diabetes insipidus in one man provided support for this hypothesis.

The precise nature of the toxic agent remains uncertain, but the results of the analyses suggest a causal relation between the presence of organic sulphur compounds and the development of symptoms. Many organic sulphur compounds are acute irritants and have specific toxic effects resulting from interference with enzyme systems. ${ }^{6}$ They are highly reactive, readily oxidised, and hence are metabolised to other toxic compounds. One oxidation product, dimethyl sulphate is recog- nised as a particular hazard because it causes considerable inflammation of mucous membranes some time after exposure with minimal irritant symptoms at the time of exposure. ${ }^{7}$ These organic sulphur compounds have a highly intense odour, and are not normally found in sewers, although small quantities can be detected as a result of anaerobic activity in sewage works. No evidence was found on any occasion of escape of domestic gas although traces of sulphides and mercaptans are present in domestic gas. No potential sources of industrial effluent have been identified in the mainly residential area. Despite considerable investigation, the source remains unknown but other possibilities which include disturbance of gas from old landfill sites by rising water levels are being investigated.

This incident has important implications for working practices within the sewer industry and compliance with the Management of Health and Safety at Work Regulations. ${ }^{8}$ It must be recognised that unknown toxic gases may be encountered within sewers and that currently used gas detection equipment is unable to identify the wide range of potential hazards. The risk assessment for such work situations should assume that any unidentified and unusual odour represents a hazard. Although use of gas detection equipment remains important for the readily identified hazards and explosive risk, adequate protection for workers investigating such odours can only be provided by appropriate training and use of positive pressure breathing apparatus.

1 Ross DJ, Sallie BA, McDonald JC. SWORD '94: surveillance of work-related and occupational respiratory disease in the UK. Occup Med 1995;45:175-8.

2 Meredith SK, McDonald JC. Work related respiratory disease in the United Kingdom, 1989-92: report on the ease in the United Kingdom, 1989-92: repor

3 Sallie BA, Ross DJ, Meredith SK, McDonald JC. SWORD '93: surveillance of work related and occupational respiratory disease in the UK. Occup Med 1994;44:177-82

4 Brooks SM, Weiss MA, Bernstein IL. Reactive airways dysfunction syndrome: persistent asthma syndrome after high level irritant exposure. Chest 1985;88:376.

5 Brooks SM. Occupational asthma. In: Weiss EB, Stein M, eds. Bronchial asthma: mechanisms and therapeutics. 3rd ed. Boston: Little Brown, 1993:594-8.

6 Sandmeyer EE. Organic sulfur compounds. In: Clayton GD, Clayton FE, eds. Patty's industrial hygiene and toxicology. 3rd revised ed. New York: J Wiley, 1981;2A: cology. $2061-96$.

7 Littler TR, McConnell RB. Dimethyl sulphate poisoning. Br f Ind Med 1955;12:54-6.

8 Health and Safety Commission. Management of the Health and Safety at Work Regulations 1992, Approved Code of Practice. London: HMSO, 1992. 